\title{
Role of Calprotectin in Diagnosis of Spontaneous Bacterial Peritonitis in Cirrhotic Patients with Ascites
}

\author{
Magdy A Gad ${ }^{1}$, Mohammad E EL-Shewi ${ }^{1}$, Jehan H Sabry ${ }^{2}$, Abdelmonem \\ ME Zawawy ${ }^{3}$ \\ ${ }^{\mathbf{1}}$ Hepatology, Gastroenterology and Infectious Diseases Department, Faculty of Medicine, \\ Benha University, Benha, Egypt. \\ ${ }^{2}$ Clinical and Chemical Pathology Departments , Faculty of Medicine, Benha University, \\ Benha,Egypt \\ ${ }^{3}$ Hepatology, Gastroenterology and Infectious Diseases Department, Shebein El-Kom Teaching \\ Hospital, Shebein El-Kom, Egypt.
}

\section{Corresponding Author: \\ Abdelmonem \\ Mohammad El-Sayed \\ El-Zawawy \\ Mobile: \\ $+201006967644$ \\ E mail: \\ Dralaa2005@yahoo.c \\ om}

Key words:

Calprotectin, Ascites, Spontaneous bacterial peritonitis
Background and study aim: The most common infection in decompensated hepatic patients with cirrhotic ascites is spontaneous bacterial peritonitis (SBP), which occurs in the absence of an evident intra-abdominal source of infection. The aim of this work is to assess the value of calprotectin in ascitic fluid in diagnosis of spontaneous bacterial peritonitis in patients with liver cirrhosis.

Patients and Methods: In this cross section study, 80 cirrhotic patients were divided into (group A) 40 patients with non SBP and (group B) 40 patients with SBP, who attended the Hepatology Department Benha University Hospital. All the patients were evaluated by thorough history, clinical examination, laboratory investigations, ultrasonongraphy, diagnostic paracentesis

\section{INTRODUCTION}

Liver cirrhosis is the clinical endstage of different entities of chronic liver disease when patients suffer from substantial mortality and morbidity, both of which are positively correlated with disease severity [1].

Ascites is the most common complication in cirrhotic patients, and around $60 \%$ of patients with compensated cirrhosis develop ascites within 10 years of disease onset [2].

Spontaneous bacterial peritonitis (SBP) is an important cause of morbidity and mortality in cirrhotic patients with ascites. SBP is estimated to affect $10 \%$ $30 \%$ of cirrhotic patients hospitalized with ascites, and mortality in this group approaches 30\% [3]. with PMNLs count and Calprotectin which was measured in $1 \mathrm{~mL}$ ascetic fluid by ELIZA.

Results: Calprotectin was high in SBP group with a highly statistical significant difference in SBP group compared to non SBP group so it can serve as a sensitive and specific diagnostic test for detection of SBP in cirrhotic patients with ascites. The sensitivity of the test was $90 \%$ with specificity of $62.5 \%$, PPV of $70.5 \%$ and NPV of $86.5 \%$ with the cut-off level were $2.98 \mathrm{ng} / \mathrm{ml}$ and the area under the curve was 0.88 .

Conclusion: Ascitic calprotectin reliably predicts PMN count $>250 / \mu \mathrm{L}$, which may prove useful in the diagnosis of SBP, especially with a readily available bedside testing device.
Many of these patients are asymptomatic, and it is therefore recommended that all patients with ascites undergo paracentesis at the time of admission to confirm the SBP status [4].

SBP is defined by the presence of more than 250 polymorphonuclear cells (PMNLS)/mm in ascitic fluid in absence of an intra-abdominal source of infection or malignancy [5].

Alternative methods using automated PMN counting [6], reagent strips [7], or ascitic lactoferrin [8], have been developed. Unfortunately, their diagnostic accuracies are limited and their use is dependent upon availability of laboratory personnel and reagents/ components from the commercial source. Therefore, 
an accurate and convenient method of rapid diagnosis of SBP remains an unmet clinical need [9].

Calprotectin, is calcium and zinc-binding protein, which was detected almost exclusively in neutrophils [10] and its presence in body fluids is proportional to the influx of neutrophils [11].

Ascitic calprotectin reliably predicts PMN count $>250 / \mu \mathrm{L}$, which may prove usefulness in the diagnosis of SBP, especially with a readily available bedside testing device [9].

\section{PATIENTS AND METHODS}

\section{Study design:}

Cross-sectional study.

\section{Patients:}

We enrolled in the study 80 cirrhotic patients selected from the Hepatology and Gastroenterology Department, Benha University Hospital in the period between April 2014 and October 2014 devided into :

Group (A): include 40 patients with decompensated cirrhosis and ascites without spontaneous bacterial peritonitis

Group (B): include 40 patients with decompensated cirrhosis and ascites with spontaneous bacterial peritonitis (PMN count in ascitic fluid $>250 / \mathrm{ml}^{3}$ with symptoms and signs suggestive of spontaneous bacterial peritonitis).

\section{Inclusion criteria:}

Ascitic patients with clinical, laboratory, ultrasongraphic findings of liver cirrhosis were included when:

- Age $>18$ years.

- Symptoms and signs suggest SBP as (fever, abdominal pain, ect.).

\section{Exclusion criteria:}

- Patients age $<18$ years.

- Recent abdominal surgery ( $<3$ months).

- Abdominal malignancy (HCC, Colorectal carcinoma, etc.).

- Intra-abdominal infection (abscess, appendicitis, cholecystitis, pancreatitis, etc.).

- History of Inflammatory Bowel Disease (Crohns disease, ulcerative colitis).

\section{Clinical and Laboratory Assessment:}

The following data were collected at the time of recruitment: age, sex, weight, complaint, present history, past history, and drug history. Clinical examination for signs of chronic liver disease (general and local examination).Laboratory examination include $\mathrm{HBsAg}$, Anti HCV, ALT, AST, albumin, PT, bilirubin (total and direct), INR, CBC, urea and creatinine .

\section{Instrumental Assessment:}

After an overnight fast, all patients underwent an ultrasound examination with single viewer operator in supine position to detect the presence of liver cirrhosis (irregular surface, irregular liver margins, coarse texture, attenuated hepatic veins, relative enlargement of caudate lobe, signs of portal hypertension (presence of abdominal collaterals or splenomegally), ascites, portal vein diameter, splenic vein diameter, the span of the right lobe in the mid clavicular line on oblique view and classified as shrunken $(<11 \mathrm{~cm})$, average $(11-15 \mathrm{~cm})$ or enlarged $(>15 \mathrm{~cm})$ and to exclude hepatic focal lesion.

\section{Diagnostic Paracentesis and PMNLs count:}

The technique of paracentesis was explained to the patient and it was done under aseptic precautions using a wide bore needle. The needle was introduced in the right lower quadrant while the patient lies in supine position. " $Z$ Tracking" technique was used to avoid post paracentesis leaks according to Webster et al. and Arnold et al. [12-13]. This technique is accomplished by displacing (with one gloved hand) the skin approximately $2 \mathrm{~cm}$ downward and then slowly inserting the paracentesis needle mounted on the syringe held in the other hand.The skin is not released until the needle has penetrated the peritoneum and fluid flows.

Ascetic fluid examination include physical examination (colour and turbidity), biochemical examination (total protein count, albumin, bilirubin, glucose and Calprotectin), cultures to detect any infecting organism(s) on MacConkey and blood agar plates and bedside blood culture were done for all cases with SBP and WBCs (total and differential) counting in ascetic fluid (SBP was fiagnosed when PMNL count in ascetic fluid more than 250 in absence of an intraabdominal source of infection or malignancy [14].

\section{Calprotectin measurement}

It was measured in $1 \mathrm{~mL}$ ascetic fluid by Enzyme-Linked Immuno Sorbent Assay. The kit was supplied from Sunred-bio, Shanghai, China. The kit uses a double-antibody sandwich enzymelinked immunosorbent assay (ELISA) to assay the level of Human Calprotectin(CALB) in 
samples. We Added Calprotectin (CALB) to monoclonal antibody Enzyme well which is precoated with Human Calprotectin (CALB) monoclonal antibody, incubation; then, we added Calprotectin (CALB) antibodies labeled with biotin, and combined with Streptavidin-HRP to form immune complex; then we carried it out incubation and washed it again to remove the uncombined enzyme. Then we added Chromogen Solution A, B, the color of the liquid changes into the blue, and at the effect of acid, the color finally becomes yellow. The chroma of color and the concentration of the Human Substance Calprotectin(CALB) of sample were positively correlated (Sunred Human (PMN Calprotectin) Elisa kit, 2014).

Specimen was kept in $-20^{\circ} \mathrm{C}$ to preserve, and repeated freeze-thaw cycles were avoided. Serum was left for coagulation at room temperature for 20 minute, then it was centrifugated for 20 minute. Supernatant was removed. plasma-use was suited EDTA or citrate plasma as an anticoagulant, mixed for 20 mins, centrifugated for 20-min. And supernatant was removed.

\section{Procedure of the test:}

1. Standard dilution: The Standard was diluted according to the following table:

\begin{tabular}{|c|c|c|}
\hline $24 \mathrm{ng} / \mathrm{ml}$ & $\begin{array}{l}\text { Standard } \\
\text { No.5 }\end{array}$ & $\begin{array}{l}120 \mu \mathrm{l} \text { Original Standard }+ \\
120 \mu \mathrm{l} \text { Standard diluents }\end{array}$ \\
\hline $12 \mathrm{ng} / \mathrm{ml}$ & $\begin{array}{l}\text { Standard } \\
\text { No.4 }\end{array}$ & $\begin{array}{l}120 \mu \mathrm{l} \text { Standard No.5 } \\
120 \mu \mathrm{l} \text { Standard diluents }\end{array}$ \\
\hline $6 \mathrm{ng} / \mathrm{ml}$ & $\begin{array}{l}\text { Standard } \\
\text { No.3 }\end{array}$ & $\begin{array}{l}120 \mu \mathrm{l} \text { Standard No.4 } \\
120 \mu \mathrm{l} \text { Standard diluent }\end{array}$ \\
\hline $3 \mathrm{ng} / \mathrm{ml}$ & $\begin{array}{l}\text { Standard } \\
\text { No. } 2\end{array}$ & $\begin{array}{l}120 \mu \mathrm{l} \text { Standard } \text { No.3 } \\
120 \mu \mathrm{l} \text { Standard diluent }\end{array}$ \\
\hline $1.5 \mathrm{ng} / \mathrm{ml}$ & $\begin{array}{l}\text { Standard } \\
\text { No.1 }\end{array}$ & $\begin{array}{l}120 \mu \mathrm{l} \text { Standard No.2 } \\
120 \mu \mathrm{l} \text { Standard diluent }\end{array}$ \\
\hline
\end{tabular}

2. The quantity of the plates was provided according to the quantities of samples and the standards. Standard was duplicated and blanked well (Sunred Human (PMN Calpretectin) Elisa kit , 2014).

\section{Samples Injection:}

A- Blank well: samples and CALB-antibody labeled with biotin, Streptavidin-HRP, only Chromogen solution $\mathrm{A}$ and $\mathrm{B}$, and stop solution are allowed; other operations are the same.

B- Standard wells: standard 50 $\mu$, Streptavidin-HRP $50 \mu \mathrm{l}$ was added (since the standard already has combined biotin antibody, it is not necessary to add the antibody);

C- Testing wells: we sampled $40 \mu$, and then we added both CALB-antibody $10 \mu 1$ and Streptavidin-HRP $50 \mu 1$. Then we sealed the sealing memberance, and gently shaking, incubated 60 minutes at $37^{\circ} \mathrm{C}$

4. Confection: the $30 \times$ washing concentrate was diluted 30 times with distilled water as standby.

5. Washing: we removed the memberance carefully, and drained the liquid, shaked away the remaining water.

6. We Added chromogen solution A $50 \mu 1$, then chromogen solution B $50 \mu 1$ to each well. Gently mixed, incubated for $10 \mathrm{~min}$ at $37^{\circ} \mathrm{C}$ away from light.

7. Stop: we Added Stop Solution $50 \mu 1$ into each well to stop the reaction (the blue changes into yellow immediately).

8. Final measurement: we take blank well as zero , measured the optical densit (OD) under 450 $\mathrm{nm}$ wavelength which should be carried out within 10min after adding the stop solution.

9. According to standards' concentration and the corresponding OD values, we calculate out the standard curve linear regression equation, and then we apply the OD values of the sample on the regression equation to calculate the corresponding sample's concentration.

\section{Calculation}

The standard density was taken as the horizontal, the OD value for the vertical, the standard curve was drawn on graph paper, the corresponding density according to the sample OD value was found by the sample OD value by the Sample curve (the result is the sample density) (Sunred Human (PMN Calprotectin) Elisa kit, 2014).

\section{Statistical analysis :}

All statistical analyses were performed using the SPSS software package, version 19.0 (SPSS Inc., Chicago, IL, United States). A P-value of less than 0.05 indicated statistical significance. Intergroup comparisons were made using the Mann-Whitney $\mathrm{U}$ test and the $\chi 2$ test where appropriate. Correlations between numerical data were determined with the Spearman's rank correlation coefficient. All hypothesis testing was two-tailed. The Bland-Altman plot was used 
to assess agreement between ELISA test results and POC test results, in which the differences between the results of the two tests for each individual patient were plotted against the corresponding mean of the two readings. The mean and SD of the differences and the limits of agreement, defined as the mean $\pm 2 \mathrm{SD}$ of the difference $(95 \% \mathrm{CI})$, were calculated. Analysis of the receiver operator characteristics (ROC) and calculation of the area under the curve (AUC) were used to evaluate the capability of calprotectin to identify a PMN count $>250 / \mu \mathrm{L}$. The ROC analysis identified the cut-off points for maximal diagnostic capability. The test characteristics of sensitivity, specificity, positive and negative likelihood ratios (LR+ and LR-), and positive and negative predictive values (NPV) were determined. Overall accuracy of the test was calculated according to the following formula: [(true positive test results + true negative test results)/total population]. As this study was exploratory in design, no formal power calculations were carried out.

\section{RESULTS}

This study was conducted on 40 patients with decompensated chronic liver disease and ascites who were subdivided into group A 40 patients with decompensated chronic liver disease and ascites without spontaneous bacterial peritonitis and group B cirrhotic patients infected with spontaneous bacterial peritonitis admitted to the Hepatology, Gastroenterology and Infectious Diseases Department, Benha University Hospital in the period between April 2014 and October 2014. Sixty one of them $(76.3 \%)$ were males and nineteen $(23.7 \%)$ were females. Their ages ranged from 43 to 75 years with a mean age of (57 \pm 7.5$)$.

Table (3) shows the result of chemical analysis of the ascetic fluid in the 2 studied groups. No statistical significant difference were elicted between the 2 groups as regards the ascetic fluid protein and LDH and glucose levels. On the other hand ascetic fluid Calprotectin was significantly higher in group A $(13.31 \pm 15.58)$ than in group $\mathrm{B}(2.9445 \pm 1.6)(\mathrm{P}<0.01)$.

ROC curves analysis (Fig. 1) identified at cut off value $2.89 \mathrm{ng} / \mathrm{ml}$ the sensitivity of calprotectin to diagnose SBP was (90\%), specificity (62.5\%) and the area under the curve was 0.88 (Table 4 ).

Table (1): Comparison between group A (patients with non SBP) and group B (SBP) regarding demographic features.

\begin{tabular}{|l|c|c|c|}
\hline Variable & $\begin{array}{c}\text { Group A } \\
\text { Non SBP } \\
(\mathbf{N = 4 0 )}\end{array}$ & $\begin{array}{c}\text { Group B } \\
\text { SBP } \\
(\mathbf{N = 4 0 )}\end{array}$ & P Value \\
\hline Female & $13(32.5 \%)$ & $6(15 \%)$ & 0.07 \\
Male & $27(67.5 \%)$ & $34(85 \%)$ & 0.07 \\
\hline Rural & $27(67.5 \%)$ & $34(85 \%)$ & 0.2 \\
Urban & $13(32.5 \%)$ & $6(15 \%)$ & $55.8 \pm 7.5$ \\
\hline Age & $58.3 \pm 8.3$ & & \\
\hline
\end{tabular}


Table (2): Comparison between group A (patients with non SBP) and group B (SBP) regarding clinical presentations

\begin{tabular}{|c|c|c|c|}
\hline Variable & $\begin{array}{c}\text { Group A Non SBP } \\
(N=40)\end{array}$ & $\begin{array}{l}\text { Group B SBP } \\
(N=40)\end{array}$ & P. Value \\
\hline $\begin{array}{l}\text { Clinical presentations: } \\
\text { Abdominal pain }\end{array}$ & $19(47.5 \%)$ & $23(57.5 \%)$ & 0.4 \\
\hline Fever & $11(27.5 \%)$ & $13(32.5 \%)$ & 0.6 \\
\hline Disturbed conscious level & $14(35 \%)$ & $7(17.5 \%)$ & 0.07 \\
\hline Vomiting & 0 & $3(7.5 \%)$ & 0.08 \\
\hline Diarrhea & $4(10 \%)$ & $8(20 \%)$ & 0.2 \\
\hline Hepatic encephalopathy & $18(45 \%)$ & $11(27.5 \%)$ & 0.1 \\
\hline Hematemesis & $6(15 \%)$ & $6(15 \%)$ & 1 \\
\hline Melena & $6(15 \%)$ & $6(15 \%)$ & 0.5 \\
\hline $\begin{array}{l}\text { Laboratory presentations: } \\
\text { Hemoglobin }(\mathrm{g} / \mathrm{dl})\end{array}$ & $9.5 \pm 0.9$ & $9.6 \pm 0.9$ & 0.8 \\
\hline $\mathrm{WBC} \times 1000 / \mathrm{mm}^{3}$ & $9.56 \pm 5.24$ & $12.81 \pm 4.58$ & $<0.01^{*}$ \\
\hline Platelet $\times 1000 / \mathrm{mm}^{3}$ & $83.83 \pm 29.03$ & $93.5 \pm 23.73$ & 0.12 \\
\hline Prothrombin time / (second) & $16.2 \pm 1.5$ & $16.6 \pm 2$ & 0.4 \\
\hline INR & $1.6 \pm 0.2$ & $1.6 \pm 0.3$ & 0.3 \\
\hline ALT (IULL) & $50.7 \pm 21.2$ & $52.1 \pm 16.3$ & 0.7 \\
\hline AST (IUlL) & $58 \pm 21$ & $53.6 \pm 17.8$ & 0.3 \\
\hline Albumin $(\mathrm{g} / \mathrm{dl})$ & $2.1 \pm 0.4$ & $2.1 \pm 0.3$ & 0.7 \\
\hline Bilirubin Total (mg/dl ) & $3.5 \pm 1.6$ & $3.8 \pm 1.7$ & 0.5 \\
\hline Urea $(\mathrm{mg} / \mathrm{dl})$ & $73.3 \pm 35.5$ & $73 \pm 20$ & 0.9 \\
\hline Creatinine $(\mathrm{mg} / \mathrm{dl})$ & $1.6 \pm 0.6$ & $1.8 \pm 0.6$ & 0.07 \\
\hline
\end{tabular}

* Significant difference

Table (3): Comparison between group A (patients with non SBP) and group B (SBP) regarding Ascitic fluid analysis

\begin{tabular}{|c|c|c|c|}
\hline Parameters & $\begin{array}{c}\text { Group A } \\
\text { Non SBP } \\
(\mathbf{N}=40) \\
(\text { Mean } \pm \text { SD })\end{array}$ & $\begin{array}{c}\text { Group B } \\
\text { SBP } \\
(\mathbf{N}=40) \\
\text { (Mean } \pm \text { SD })\end{array}$ & $P$ value \\
\hline Ascitic fluid protein $(\mathrm{g} / \mathrm{L})$ & $1.5 \pm 0.5$ & $1.3 \pm 0.4$ & 0.09 \\
\hline Ascitic fluid Glucose (g/L) & $156.8 \pm 63$ & $146.9 \pm 49.3$ & 0.4 \\
\hline Ascitic fluid LDH (IU/L) & $185.3 \pm 64.9$ & $201.6 \pm 55.9$ & 0.2 \\
\hline Ascitic fluid Calprotectin Elisa (ng) & $2.9445 \pm 1.6$ & $13.31 \pm 15.58$ & $<0.01$ \\
\hline
\end{tabular}

Table (4): Cut off value, sensitivity, specificity and accuracy of ascetic fluid Calprotectin to diagnose SBP

\begin{tabular}{|c|c|c|c|c|c|c|}
\hline Cut of value & Sensitivity & specificity & PPV & NPV & AUC & P \\
\hline 2.89 & $90 \%$ & $62.5 \%$ & $70.5 \%$ & $\mathbf{8 6 . 2 \%}$ & $\mathbf{0 . 8 8}$ & $<0.001 * *$ \\
\hline
\end{tabular}




\section{** Highly Significant difference}

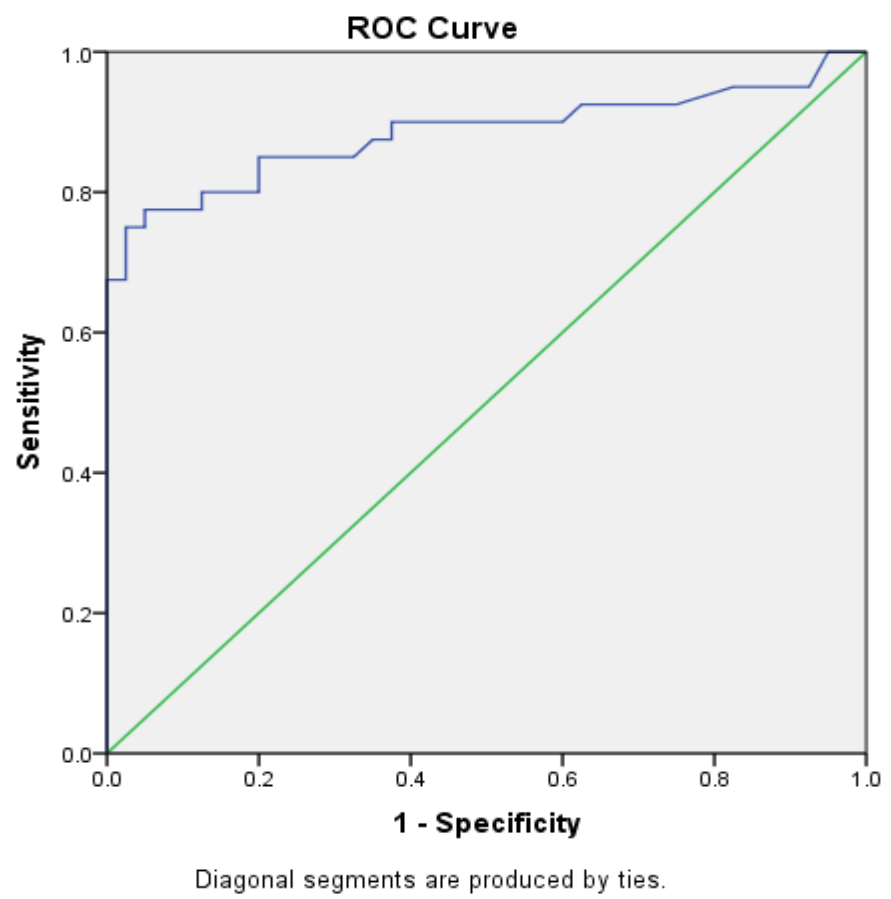

Figure (1): ROC curve for diagnosis of SBP by ascetic fluid calprotectin by Elisa test.

\section{DISCUSSION}

This study was conducted to estimate the role of ascitic fluid calprotectin level for diagnosis of SBP and to identify a cut-off level of ascitic fluid calprotectin that can be used for development of a rapid bed side test.

After informed medical consent, 80 patients with decompensated liver disease and ascites who were admitted at the Hepatology and Gastroenterology department Benha University Hospital in the period between April 2014 and October 2014 were selected.

These patients divided into:

- Group (A): include 40 patients with decompensated cirrhosis and ascites without spontaneous bacterial peritonitis.

- Group (B): include 40 patients with decompensated cirrhosis and ascites with spontaneous bacterial peritonitis (PMN count in ascitic fluid $>250 / \mathrm{ml}^{3}$ with symptoms and signs suggestive of spontaneous bacterial peritonitis).

Their ages ranged from 43 to 87 years $(55.75 \pm$ 7.5). 19(23.7\%) of them were females and 61 $(76.3 \%)$ were male as shown in table (2).

In this study mean age of patients in group A $(58.3 \pm 8.3)$ and mean age of patients in group B
$(55.8 \pm 7.5)$ was without statistically significant difference.

The present study revealed that, SBP was common in males $(76.3 \%)$ than females $(23.7 \%)$ and it was not influenced by the age as shown in table (1). This result was in agreement with the study done by Angeli et al. [15] who stated that, SBP was frequent in males and was not affected by the age.

Puri et al. [16] had founded that age seem to have no effect on the incidence of SBP.

This study revealed, the etiology of chronic liver disease were $96.3 \%$ due to $\mathrm{HCV}$ infection and $3.8 \%$ due to HBV infection and this was documented by Strickland [17] who stated that $90 \%$ of the chronic liver diseases were due to $\mathrm{HCV}$ infection.

Regarding the clinical presentations of the patients, analysis of the results showed that, fever $(32.5 \%)$ and abdominal pain $(57.5 \%)$ were the main clinical presentations in patients with SBP compared to non SBP group as shown in table (2). This could be explained by Rimola and Navasa [18] who said that, the clinical picture of SBP is extremely broad and very variable and a very high degree of clinical suspicion is required for diagnosis. 
Abdominal pain was detected in $57.5 \%$ of SBP group. This result was close to that reported by the results elicited by Llovet et al. [19] who stated that, abdominal pain was detected in 52\% of SBP cases. But, Wallersted et al. [20] stated that, abdominal pain were detected in $70 \%$ of SBP cases.

Hepatic encephalopathy was detected in $27.5 \%$ of SBP cases and $45 \%$ of non SBP cases without statistically significant difference. These results were close to that reported by Wallerstedt et al. and Nobre et al. [20,21] who stated that, there was no difference in incidence of hepatic encephalopathy in cases with and without SBP.

Regarding the parameters of laboratory investigation there is no significant statistical difference with hemoglobin and platelets $(\mathrm{P}$ value $>0.05)$ but there was significant difference between both groups in total leucocytic count ( $\mathrm{P}$ value $<0.01$ ) as shown in table (2). This result was in agreement with that reported by Rodriguez et al. [22] who detected leucocytosis in their SBP cases with significant difference when compared to non SBP cases.

Regarding liver function tests, no statistically significant differences were recorded in all parameters as shown in table (2). Casafont et al. [23] found no significant difference in liver biochemistry. These results were in agreement with those reported by Runyon et al. [24] who stated that, prolonged prothrombin time and hypoalbuminaemia are not related to SBP per se, but rather to the underlying liver disease.

The relation between occurrence of SBP and severity of liver disease showed that, $12.5 \%$ and 87.5\% of SBP cases had Child Pugh class B and $\mathrm{C}$ respectively, This result came in accordance with that reported by Rodriguez et al. [22] who elicited that, SBP patients usually had ChildPugh class B or C.

Physical examination of ascitic fluid revealed turbid fluid in $20 \%$ of patients of SBP with statistical significance when compared to the non SBP group. In agreement with this result, Albillos et al. [25] observed that, the appearance of ascitic fluid in patient with SBP is usually turbid. Moreover, Runyon [26] reported that, the opacity of many cloudy ascitic fluid specimens is caused by neutrophils. Moreover, Chinnock and Hendey [27] in a retrospective review of 916 outpatient ascitic fluid samples showed that, abnormal ascitic fluid appearance had a sensitivity of
$98.1 \%$ and a specificity of $22.7 \%$ in the detection of SBP.

To avoid diagnostic delay, it has been proposed that automated PMN counting should replace the laborious and time-consuming manual cell counting technique [6]. However, despite the potential benefit of automated cell counters in clinical practice, widespread use of this technology is limited by the cost of the sophisticated laboratory equipment and requirement for trained operators.

This prospective study evaluated the diagnostic utility of measuring calprotectin in ascites to identify ascitic PMN counts $>250 / \mathrm{ml}^{3}$ in patients referred to Hepatology Department, and provides the following new information: Patients with an elevated PMN count $\left(>250 / \mathrm{ml}^{3}\right)$ had higher ascitic calprotectin levels than those with normal cell counts; this finding indicates that ascitic calprotectin levels correlate well and reliably with PMN count as shown in table (3). It is clinically significant that calprotectin levels in ascitic patients can identify elevated PMN counts using both laboratory based ELISA and bedside POC testing. Indeed, ascitic calprotectin may serve as a surrogate marker for PMN count and would be amenable to routine SBP screening, especially when measured by a bedside test.

In this study, ascitic fluid calprotectin was detected in both groups, there was highly significant increase in ascitic fluid calprotectin in SBP group when compared with non SBP group $(13.31 \pm 15.58 \& 2.9445 \pm 1.6)$ respectively as shown in table (3).The sensitivity of the test was $90 \%$ with specificity of $62.5 \%$, with the cut-off level was $2.89 \mathrm{ng} / \mathrm{ml}$, positive predictive value $70.5 \%$ and negative predictive value $86.2 \%$ as shown in table (4).

A study done by Burri et al. [9] stated that using the optimal cut-off value for ELISA $(0.63 \mu \mathrm{g} / \mathrm{mL})$, ascitic fluid calprotectin had $94.8 \%$ sensitivity, $89.2 \%$ specificity, positive and negative likelihood ratios of 8.76 and 0.06 respectively, positive and negative predictive values of $60.0 \%$ and $99.0 \%$ respectively, and $90.0 \%$ overall accuracy. The results of this study were in disagreement with that reported by Rito Norbe et al. [28] who stated that, the diagnostic accuracy of Calprotectin are limited in ascitic fluid infection.

The results from our current study confirm the findings reported by Burri et al. [9]. Specifically, we show that measurement of Calprotectin, a 
leukocyte specific protein, may serve as a surrogate marker for the PMN count in ascetic fluid. A particular strength of our study is the quantitative measurement of Calprotectin by a laboratory-based ELISA test. Rapid bedside measurement is advantageous for hospitalized patients, as it supports early antibiotic intervention and limits unnecessary treatments. Further studies are warranted to define a clinically useful cut-off for the diagnosis of SBP in cirrhotic patients with ascites.

\section{ACKNOWLEDGMENT}

The authors would thank the staff of the Tropical Medicine Department, and the laboratory technicians, for their valuable efforts.

Funding: None.

Conflicts of interest: None.

Ethical approval: Approved.

\section{REFERENCES}

1. D’Amico G, Garcia-Tsao G, Pagliaro L. Natural history and prognostic indicators of survival in cirrhosis: a systematic review of 118 studies. $J$ Hepatol 2006; 44: 217-31.

2. Gines P, Arroyo V, Quintero E, Planas R, Bory F, Cabrera $\mathrm{J}$ et al. Comparison of paracentesis and diuretics in the treatment of cirrhotics with tense ascites results of a randomized study. Gastroenterology 1987; 93 : 234 - 241.

3. Thuluvath PJ, Morss S, Thompson R . Spontaneous bacterial peritonitis in hospital mortality, predictors of survival and health care costs from 1988 to 1998. Am. J. Gastroenterol 2001; 96: 1232- 1236.

4. Rimola A, Garcia-Tsao G, Navasa M, Piddock, LJ, Planas R, Bernard B et al. Diagnosis treatment and prophylaxis of spontaneous bacterial peritonitis aconsensus document. J. Hepatology 2000; 32: 142 $-153$.

5. Arroyo V, Bataller R, Gines P. Spontaneous bacterial peritonitis $\mathrm{O}$ Grady and Lake $\mathrm{s}$ comprehensive clinical hepatology, $1^{\text {st }}$ ed. Barcelona: Mosby 2000: 7.10-7.14.

6. Cereto F, Genescà J, Segura R. Validation of automated blood cell counters for the diagnosis of spontaneous bacterial peritonitis. Am J Gastroenterol 2004; 99: 1400 .
7. Nousbaum JB, Cadranel JF, Nahon P, Khac E.N, Moreau R, Thévenot $\mathrm{T}$ et al. Diagnostic accuracy of the Multistix 8 SG reagent strip in diagnosis of spontaneous bacterial peritonitis. Hepatology 2007; 45: 1275-1281.

8. Parsi MA, Saadeh SN, Zein NN, Davis GL, Lopez $\mathrm{R}$, Boone $\mathrm{J}$ et al. Ascitic fluid lactoferrin for diagnosis of spontaneous bacterial peritonitis. Gastroenterology 2008; 135: 803-807.

9. Burri E, Schutle F, Muser J, Meier R, Beglinger C. Measurement of calprotectin in ascetic fluid to identify elevated polymorphonuclear cell count. $J$ Gastroentrol 2013 ; 19(13) : 2028-2036.

10. Foell, D, Frosch, M, Sorg, C, Roth, J. Phagocytespecific calcium-binding S100 proteins as clinical laboratory markers of inflammation. Clin Chim Acta 2004; 344: 37-51.

11. Soyfoo, M.S, Roth, J, Vogl, T, Pochet, R, Decaux, G. Phagocytespecific S100A8/A9 protein levels during disease exacerbations and infections in systemic lupus erythematosus. J Rheumatol 2009; 36: 2190-2194.

12. Webster ST, Brown KL, Lucey MR , Nostrant, TT. Haemorrhagic complications of large volume abdominal paracentesis. Am J Gastroenterol 1996; $92: 366-368$.

13. Arnold C, Haag K, Blum H.E, Rossle M. Acute haemoperitoneum after large- volume paracentesis. Gastroenterology 1997; 113 : 978 - 982.

14. Arroyo V, Bataller R, Gines P. Spontaneous bacterial peritonitis $\mathrm{O}$ Grady and Lakes comprehensive clinical hepatology, $1^{\text {st }}$ ed. Barcelona: Mosby 2000: 7.10-7.14.

15. Angeli K.L, Moore KP, Moreau R. Management of ascites, spontaneous bacterial peritonitis, and hepatorenal Syndrome. World J Gastroenterol 2000; (12), 232_312.

16. Puri AS, Puri J, Ghoshal UC, Sharma, B.C, Saraswat, VA, Ayyagari A et al. Frequency, microbial spectrum and outcome of spontaneous bacterial peritonitis. Indian J Gastroenterol 1996; 15(3): 86-89.

17. Strickland GT. Liver disease in Egypt: hepatitis C superseded schistosomiasis as a result of iatrogenic and biological factors. Hepatology 2006; 34(5), 915-922.

18. Rimola, A, Navasa, M. Infection in liver disease. In: Oxford textbook of clinical hepatology. Bircher J, Benhamou J, McIntyre N, Rizzetto M, Rodes J, editors. New York: Oxford University Press.1999; $1861-76$. 
19. Llovet J, Moitinho E, Sala M, Bataller R, RodríguezIglesias P, Castells A et al. Prevelance and prognostic value of hepato cellular carcinoma in cirrhotic patients presenting with spontaneous bacterial peritonitis. J. Hepatology 2000; 33: 42329.

20. Wallersted S, Olsson R, Simern M, Broomé U, Wahlin S, Lööf L et al. Abdominal tender-ness in ascites patients indicates spontaneous bacterial peritonitis. Eur. J. Internal medicine 2007; 18: 4447.

21. Nobre SR, Cabral JE, Gomes JJ, Leitão MC. Inhospital mortality in spontaneous bacterial peritonitis: a new predictive model. Eur $J$ Gastroenterol Hepatol.2008; 20:1176-1181.

22. Rodriguez-Ramos C, Galan F, Diaz F, Costaner A . Expression of pro inflammatory cytokines and their inhibitors during the course of spontaneous bacterial peritonitis. Dig . Dis. Sci.2001; 46, 8, 1668 - 76.

23. Casafont F, Coworkers C, Fernande MD. Overview on cirrhotic patients with spontaneous Bacterial peritonitis .Dig. Dis. Sci. 1991; 44(10): 1985-89.

24. Runyon BA, Akriviadis EA, Sattler FR, Cohen J. Ascitic fluid and serum cefotaxime and desacetyl cefotaxime levels in patients treated for bacterial peritonitis. Dig. Dis. Sci. 1991; 12 : 1782 - 1786.
25. Albillos A, Cuervas-Mons V, Millan, L, Cantón, $\mathrm{T}$, Montes J, Barrios $\mathrm{C}$ et al. Ascitic fluid polymorphonuclear cell count and serum to ascites ablumin gradient in the diagnosis of bacterial peritonitis. Gastroenterol 1999 ; 98: 134 - 140.

26.Runyon BA. Ascites and spontaneous bacterial peritonitis. In Gastrointestinal and liver disease pathology, Diagnosis, Management, Feldman M, Friedman L and Sleisenger M (eds). Philadelphia, London, Sydney, Toronto 2002 : 1517.

27. Chinnock B, Hendey M. Can clear ascitic fluid appearance rule out spontaneous bacterial peritonitis. Am. J. Emerg. Med 2007; 25: 934- 937.

28. Rito Norbe S, Pina Cabral J.E, Sofia C, Correia Leitao M. Value of reagent strips and calprotectin role in the rapid diagnosis of spontaneous bacterial peritonitis. Hepato-gastroenterology 2008; 55(84): 1020-1023.

Peer reviewer: Rashed Hasan, Professor of Tropical Medicine and Hepatogastroenterology, Faculty of Medicine, Zagazig University, Egypt. Editor: Tarik Zaher, Professor of Tropical Medicine and Hepatogastroenterology, Faculty of Medicine, Zagazig University, Egypt 